\title{
Synthesis and Properties of Multiblock Copolymers of Styrene and Propylene Oxide
}

\author{
Hongquan XIE and Xin CHEN
}

Hubei Research Institute of Chemistry, Wuhan, China

(Received February 12, 1987)

\begin{abstract}
Multiblock copolymers of styrene and propylene oxide were synthesized by coupling together polypropylene glycol and telechelic dihydroxyl polystyrene with 2,4-toluene diisocyanate (TDI) as the coupling agent. The results showed that it was better to terminate the telechelic dihydroxyl polystyrene with TDI first, then react with polypropylene glycol. The copolymer obtained in this two-step method possesses less homopolymers than that obtained when all the three reagents reacted together in one step. The crude product can be purified by extractions with absolute ethyl alcohol and decalin in order to remove the unreacted polypropylene glycol and polystyrene respectively. The purified products were characterized by IR, ${ }^{1} \mathrm{H}$ NMR, GPC, membrane osmometry, elemental analysis, and shown to be multiblock copolymers of styrene and propylene oxide. The multiblock copolymer exhibits two glass transition temperatures $\left(T_{\mathrm{g}}\right)$ and behaves like a thermoplastic elastomer at $20-30 \%$ polystyrene content. Addition of $2 \%$ of the copolymers to the blends of polystyrene and epichlorohydrin rubber improves evidently their mechanical properties and causes the two $T_{\mathrm{g}}$ 's become closer.

KEY WORDS Block Copolymer / Styrene-Propylene Oxide Block Copolymer / Thermoplastic Elastomer / Compatibilizer /
\end{abstract}

Szwarc and Richards ${ }^{1}$ attempted to synthesize a triblock copolymer of styrene and propylene oxide using sodium $\alpha$-methylstyrene tetramer as an initiator, but failed due to the chain transfer reaction of propylene oxide. Tobolsky et al. ${ }^{2}$ obtained the block copolymer through reaction of isocyanate terminated polypropylene glycol with $t$-butyl hydrogen peroxide to form a product which then initiated the radical polymerization of styrene. The product obtained after fractionation was shown to be block copolymer of styrene and propylene oxide. Kawamura et al. ${ }^{3}$ used 4,4'diisocyanate diphenyl disulfide as an initiator for photopolymerization of styrene and thus obtained telechelic diisocyanate polystyrene in $50 \%$ conversion, which then reacted with polypropylene glycol to form block copolymer. Hsiue ${ }^{4}$ synthesized styrene-propylene oxide-styrene triblock copolymer by first preparing isocyanate terminated polystyrene which then reacted with polypropylene glycol. The molecular weight of the triblock copolymer was reported to be $8 \times 10^{4}$.

This paper deals with the synthesis of multiblock copolymer of styrene and propylene oxide by coupling reaction of telechelic dihydroxyl polystyrene, TDI and polypropylene glycol and also the study of their properties in order to obtain a new polymeric material containing no double bonds for use as a thermoplastic elastomer and a compatibilizer in the blending of epichlorohydrin rubber and polystyrene.

\section{EXPERIMENTAL}

\section{Materials}

Telechelic dihydroxyl polystyrenes with different molecular weight from $0.86 \times 10^{4}$ to 
$1.65 \times 10^{4}$ were prepared by anionic polymerization of styrene using lithium $\alpha$-methylnaphthalene as a dianionic initiator, then terminating with ethylene oxide and neutralizing with acetic acid. ${ }^{5}$ Polypropylene glycol with number-average molecular weight $\left(\bar{M}_{n}\right)$ of 2000 was produced by Dow Chemical Company and dried by azeotropic distillation with toluene. Functionality of the above two prepolymers was determined by isocyanate method $^{5}$ to be $2.00 \pm 0.02$. 2,4-Toluene diisocyanate (TDI) was purified by distillation under reduced pressure. The distillate at $105^{\circ} \mathrm{C} / 4 \mathrm{mmHg}$ was collected and preserved under nitrogen atmosphere and protection from light. Toluene was dried by standing over 4A molecular sieve overnight. Dibutyl dilaurate and epichlorohydrin rubber with viscosity-average molecular weight $\left(\bar{M}_{v}\right)$ of $6 \times 10^{5}$ and polystyrene with weight-average molecular weight $\left(\bar{M}_{w}\right)$ of $1 \times 10^{5}$ were used as received.

\section{One-Step Method for Synthesis of the Block Copolymers}

The telechelic dihydroxyl polystyrene was dissolved in $25 \mathrm{ml}$ dried toluene to which the dried polypropylene glycol was added under stirring. The total amount of the two prepolymers was $10 \mathrm{~g}$. Dibutyltin dilaurate $(0.2 \%$ based on the solution) was then introduced via a syringe and the mixture heated to $60^{\circ} \mathrm{C}$. Then a calculated amount of TDI was added under stirring and the reaction was carried out at $60^{\circ} \mathrm{C}$ for 2 days. Samples were taken out for analysis of isocyanate group and viscosity of the solution at intervals. The isocyanate group was determined by back titration of $n$ butylamine after reaction.

\section{Two-Step Method for Synthesis of the Block Copolymers}

The telechelic dihydroxyl polystyrene was dissolved in $25 \mathrm{ml}$ dried toluene to which dibutyltin dilaurate solution was added. A calculated amount of TDI based on total hydroxyl group content of both telechelic dihydroxyl polystyrene and polypropylene glycol according to the weight ratio of PSt/PPO desired was added under stirring at $40^{\circ} \mathrm{C}$. After reaction for $2 \mathrm{~h}$, polypropylene glycol was then introduced and the reaction carried out for $46 \mathrm{~h}$ at $60^{\circ} \mathrm{C}$. The total amount of the two prepolymers was $10 \mathrm{~g}$.

\section{Purification of the Block Copolymers}

The polymerization solution was added slowly to 4 times its volume of ethyl alcohol. After centrifuging, the precipitate was washed several times with ethyl alcohol in order to remove unreacted polypropylene glycol. After drying, the precipitate was extracted with decalin in order to remove unreacted polystyrene. The purified product was then washed with ethyl alcohol and dried under vacuum.

\section{Characterization of the Block Copolymers}

The molecular weight and molecular weight distribution of telechelic dihydroxyl polystyrene were determined by GPC on LC-4A liquid chromatography apparatus with differential refractive index detector. The numberaverage molecular weight of the block copolymer was measured by Bruss membrane osmometer. The IR spectra of the block copolymers were obtained with SP3-300 spectrophotometer and ${ }^{1} \mathrm{H}$ NMR spectra recorded by a EM-360 spectrometer $(60 \mathrm{MHz})$. Oxygen content of the block copolymer was analyzed by automatic elemental analyzer and composition of the polyether in the copolymer can thus be calculated. Glass transition temperatures were measured by DDV-III-EA apparatus with a heating rate of $3^{\circ} \mathrm{C} \mathrm{min}{ }^{-1}$ at $110 \mathrm{~Hz}$. Mechanical properties were measured by DL-250A tensile tester with a stretching speed at $300 \mathrm{~mm} \mathrm{~min}^{-1}$. The specimens were prepared by pressing under pressure at $110^{\circ} \mathrm{C}$ for $20 \mathrm{~min}$ and annealing to room temperature. Melt index was determined by XRZ-400-1 melt index apparatus at $145^{\circ} \mathrm{C}$ with $2.1 \mathrm{~kg}$ load.

Blending of epichlorohydrin rubber and 
polystyrene was carried out on a hot mill at $155^{\circ} \mathrm{C}$ for $5 \mathrm{~min}$. Intrinsic viscosity $[\eta]$ was determined in toluene at $25^{\circ} \mathrm{C}$.

\section{RESULTS AND DISCUSSION}

\section{One-Step Method}

Figure 1 shows the relation between the reaction time and the conversion of isocyanate group and the relative viscosity of the polymerization solution. It can be seen that at the beginning of reaction conversion of $\mathrm{NCO}$ group rose very quickly to about $80 \%$ within $2 \mathrm{~h}$. Then the reaction proceeded slowly so that the rest of NCO groups needed $46 \mathrm{~h}$ to react completely. This is attributed to the lower reactivity of the $\mathrm{NCO}$ groups in the ortho position of TDI than that in the para position and also to the lower reactivity of secondary hydroxyl groups of polypropylene glycol than

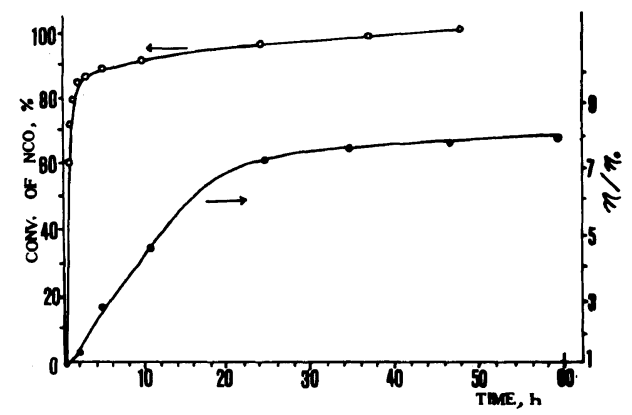

Figure 1. Relation between reaction time and the conversion of NCO groups, and relative viscosity of the polymerization solution in one-step reaction.

Table I. Effects of molar ratio of $\mathrm{NCO} / \mathrm{OH}$ on one-step reaction

\begin{tabular}{|c|c|c|c|c|}
\hline \multirow{2}{*}{$\mathrm{NCO} / \mathrm{OH}$} & \multirow{2}{*}{$\frac{[\eta]}{\mathrm{dl} \mathrm{g}^{-1}}$} & \multirow{2}{*}{$\frac{\text { Oxygen content }}{\%}$} & \multicolumn{2}{|c|}{$\mathrm{PPO} / \%$} \\
\hline & & & Exptl & Calcd \\
\hline 1.00 & 0.87 & 15.21 & 52.3 & 65.6 \\
\hline 1.05 & 1.05 & 15.75 & 54.2 & 65.4 \\
\hline 1.10 & 1.42 & 16.49 & 56.7 & 65.2 \\
\hline 1.15 & 2.01 & 19.00 & 65.3 & 65.0 \\
\hline 1.20 & $\infty$ & - & - & - \\
\hline 1.30 & $\infty$ & - & - & - \\
\hline
\end{tabular}

that of primary hydroxyl end groups of both the polystyrene and polypropylene glycol. The viscosity of the polymerization solution increases gradually in the first $20 \mathrm{~h}$ and then slowly. Increase of viscosity implies the coupling of the end groups of the prepolymers. In the last period both conversion of $\mathrm{NCO}$ and viscosity increased slowly due to lower concentration of functional groups.

The effect of molar ratio of $\mathrm{NCO} / \mathrm{OH}$ on the one-step reaction was shown in Table I. When $\mathrm{NCO} / \mathrm{OH}$ was $=1.10$, the coupling reaction was not complete and the content of polyether (PPO) was lower than the calculated value. When $\mathrm{NCO} / \mathrm{OH}=1.15$, the content of polyether units approached to the calculated value. But if $\mathrm{NCO} / \mathrm{OH}$ was larger than 1.15 , gelation occurred. The reason for $\mathrm{NCO} / \mathrm{OH}$ in excess is probably due to that a small amount of impurities including water remaining in the reagents consumed some TDI.

Amount of toluene used as solvent also has some effect on the coupling reaction. If toluene used was too little, there appeared some white precipitates in the course of the reaction and no product with higher molecular weight was obtained. The relation between the amount of

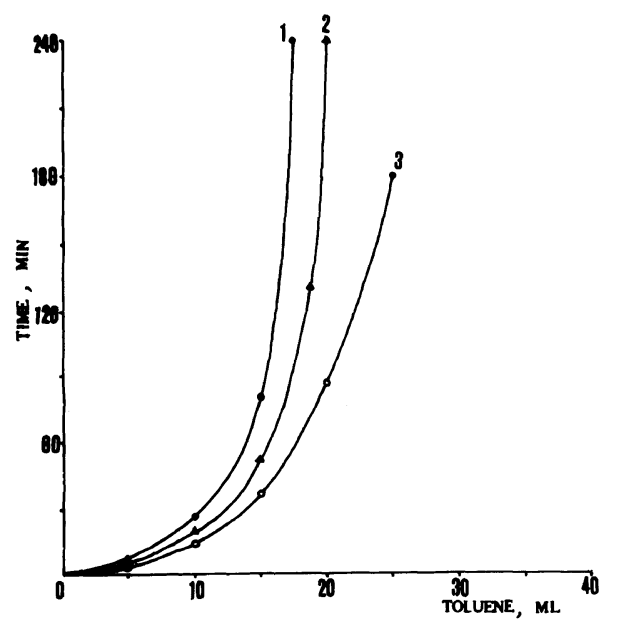

Figure 2. Effects of the amount of solvent and the molecular weight of polystyrene on the time of precipitation during one-step reaction. $\bar{M}_{n} \times 10^{-4}$ of PSt: 1 , $0.84 ; 2,1.52 ; 3,2.40$. 
toluene used, the molecular weight of the telechelic dihydroxyl polystyrene and the time when the white precipitate began to occur was shown in Figure 2. The larger the molecular weight of polystyrene was, the more easily the precipitate formed or the more solvent was needed to prevent from precipitation.

\section{Two-Step Method}

In order to prevent the telechelic dihydroxyl polystyrene from coupling together, a two-step coupling method was used, i.e., the $\alpha, \omega$-dihydroxyl polystyrene was first reacted with TDI to form poly(styrene diisocyanate), which then reacted with polypropylene glycol. It

Table II. Effects of reaction temperature on the block copolymers obtained by two-step method ${ }^{\mathrm{a}}$

\begin{tabular}{|c|c|c|c|c|}
\hline \multirow{2}{*}{$\frac{\mathrm{PSt} / \mathrm{PPO}}{\text { wt ratio }}$} & \multirow{2}{*}{$\frac{\text { Temp at 2nd step }}{{ }^{\circ} \mathrm{C}}$} & \multirow{2}{*}{$\frac{[\eta]}{\mathrm{dl} \mathrm{g}^{-1}}$} & \multicolumn{2}{|c|}{$\mathrm{PPO} / \%$} \\
\hline & & & Exptl & Calcd \\
\hline $2 / 8$ & 40 & 1.64 & 53.4 & 73.8 \\
\hline $2 / 8$ & 60 & 2.23 & 69.5 & 73.8 \\
\hline $3 / 7$ & 40 & 1.58 & 48.8 & 65.0 \\
\hline $3 / 7$ & 60 & 2.10 & 65.1 & 65.0 \\
\hline
\end{tabular}

a $\mathrm{NCO} / \mathrm{OH}=1.15 . \bar{M}_{n}$ of PSt $=1.12 \times 10^{4}$. The first step was at $40^{\circ} \mathrm{C}$ for $2 \mathrm{~h}$ and the second step for $46 \mathrm{~h}$.

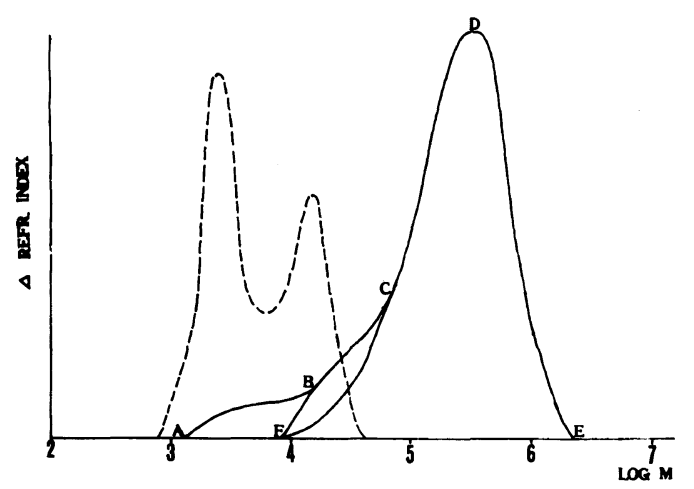

Figure 3. GPC curves of a product obtained in onestep method before and after extractions: Curve ABCDE, crude product before extraction; FBCDE, after extraction with ethyl alcohol; FCDE, after extractions with ethyl alcohol and decalin. Dashed curve, GPC curve of a mixture of the polypropylene glycol and telechelic dihydroxyl polystyrene. was confirmed by GPC that no coupled polystyrene was produced.

It is better to carry out the coupling reaction at $60^{\circ} \mathrm{C}$ than at $40^{\circ} \mathrm{C}$, since the molecular weight of the product obtained at $60^{\circ} \mathrm{C}$ is higher than that at $40^{\circ} \mathrm{C}$ and the polyether content of product prepared at $60^{\circ} \mathrm{C}$ was nearer to the calculated value, as shown in Table II. This implies that the coupling reaction seems not complete at $40^{\circ} \mathrm{C}$ within $46 \mathrm{~h}$.

\section{Purification of the Block Copolymers}

GPC curve of the crude product obtained by one-step method (curve ABCDE in Figure 3) was compared with that of a mixture of telechelic dihydroxyl polystyrene and polypropylene glycol. This indicates that there is still some homopolymers existing in the crude product obtained by one-step method.

The crude product can be purified by extractions with ethyl alcohol and decalin, as demonstrated by GPC curves in Figure 3. Curve FBCDE represents the GPC curve of the product after extraction with ethyl alcohol. The GPC curve of the product after extractions with ethyl alcohol and decalin is represented by FCDE curve which shows no homopolymers as compared with dashed curve. The products obtained by two-step method usually contain only a little homopolymers.

\section{Characterization of the Purified Block Co- polymers}

The purified block copolymers were characterized by IR and ${ }^{1} \mathrm{H}$ NMR. The IR spectra showed the absorption peaks of urethane groups at 3308 and $1725 \mathrm{~cm}^{-1}$, those of phenyl groups at 3025, 3060, 3080, 1600, 1530, 775, and $695 \mathrm{~cm}^{-1}$ and those of ether groups at $1050-1150 \mathrm{~cm}^{-1} \cdot{ }^{1} \mathrm{H}$ NMR spectra indicated the presence of phenyl protons at $\delta 6.5$ and $\delta 6.95$, alkyl protons next to oxygen at $\delta 3.35$ and $\delta 3.55$ and protons from $\mathrm{CH}_{3}$ and $\mathrm{CH}_{2}-$ $\mathrm{CH}$ at $\delta 1.10$. These data demonstrate that the purified products are indeed block copolymers of styrene and propylene oxide coupled by 
Table III. Structural parameters of the block copolymers obtained by two-step method

\begin{tabular}{lccc}
$\begin{array}{c}\text { Wt ratio } \\
\text { PSt/PPO }\end{array}$ & $\begin{array}{c}\bar{M}_{n}{ }^{\mathrm{a}} \text { of used } \\
\text { PSt } \\
\times 10^{-4}\end{array}$ & $\begin{array}{c}\bar{M}_{n}{ }^{\mathrm{b}} \text { of block } \\
\text { copolymer } \\
\times 10^{-4}\end{array}$ & $\begin{array}{c}\text { Calcd. No. of } \\
\text { blocks in the } \\
\text { copolymers }^{\mathrm{c}}\end{array}$ \\
\hline $2.1 / 7.9$ & 1.14 & 14.5 & 6.34 \\
$3 / 7$ & 1.14 & 7.92 & 5.16 \\
$3 / 7$ & 1.14 & 15.4 & 9.10 \\
$3 / 7$ & 0.86 & 14.7 & 11.3 \\
$3 / 7$ & 1.65 & 13.5 & 5.90 \\
$4 / 6$ & 1.14 & 14.9 & 11.5 \\
\hline
\end{tabular}

a GPC. b Bruss membrane osmometry.

c The value was calculated as follows: No. of blocks in the copolymer $=$ No. of PSt in the block copolymer + No. of coupled PPO in the block copolymer. No. of coupled PPO in the block copolymer $=$ No. of PSt in the block copolymer 1.

$$
\begin{aligned}
\text { No. of PSt }= & \frac{\text { wt of PSt }}{\text { wt of PSt }+ \text { wt of PPO }} \\
& \times \frac{\bar{M}_{n} \text { of copolymer }}{\bar{M}_{n} \text { of PSt }} .
\end{aligned}
$$

TDI.

Structural parameters of the block copolymers are listed in Table III. It can be deduced that: (1) the block copolymers are rather multiblock copolymers; (2) when the weight ratio of PSt/PPO and also $\bar{M}_{n}$ of the telechelic dihydroxyl polystyrene were kept unchanged, both the average number of the polystyrene blocks and the length of the coupled PPO block decrease with decreasing $\bar{M}_{n}$ of the block copolymers.

\section{Properties of the Multiblock Copolymers}

Dynamical mechanical analysis of the purified block copolymers shows that they exhibit two transition temperatures at 108 and $-47^{\circ} \mathrm{C}$, which correspond to the $T_{\mathrm{g}}$ 's of polystyrene and polypropylene oxide respectively. This implies that there occurs microphase separation in the block copolymer.

The mechanical properties of the block copolymer with $\bar{M}_{n}$ of $14.5 \times 10^{4}-15.5 \times 10^{4}$ were listed in Table IV, which shows that when polystyrene content is $20-30 \%$, the copoly-
Table IV. Effects of weight ratio of PSt/PPO on

\begin{tabular}{|c|c|c|c|c|}
\hline PSt/PPO & $\begin{array}{c}\text { Tensile } \\
\text { strength }\end{array}$ & Elongation & $\begin{array}{l}\text { Permanient } \\
\text { set }\end{array}$ & Melt index \\
\hline wt ratio & & $\%$ & $\%$ & $\mathrm{~g} / 10 \mathrm{~min}$ \\
\hline $2 / 8$ & 7.6 & 667 & 16 & 3.6 \\
\hline $2.5 / 7.5$ & 10.5 & 634 & 14 & 4.0 \\
\hline $3 / 7$ & 13.1 & 402 & 10 & 5.4 \\
\hline $4 / 6$ & 14.6 & 134 & 36 & 6.3 \\
\hline
\end{tabular}
mechanical properties of the block copolymers

mers behave like thermoplastic elastomers, exhibiting high elongation, low permanent set and suitable melt index. With increase of polystyrene content, the tensile strength and modulus of the block copolymers increase, while elongation decreases. When the polystyrene content reaches $40 \%$, elongation decreases evidently, while the tensile strength and permanent set become larger, and so the block copolymers belong to toughened plastics. These behaviors are similar to that of SBS block copolymers ${ }^{6}$ and the superstructure of the multiblock copolymers can be described as polystyrene domains, formed by aggregation of polystyrene blocks, dispersed in a continuous phase of polypropylene oxide. When the polystyrene content is above $40 \%$, the polystyrene domains may be connected together and tend to form continuous phase, showing the properties of plastics.

$\bar{M}_{n}$ of the polystyrene block exerts an important influence on the mechanical properties of the block copolymers (Table V). When $\bar{M}_{n}$ of the polystyrene blocks is $>1.14 \times 10^{4}$, tensile strength increases slowly with $\bar{M}_{n}$ of the polystyrene blocks; but when $\bar{M}_{n}$ of the polystyrene blocks is $<0.86 \times 10^{4}$, tensile strength of the copolymer decreases significantly and permanent set tends to increase with decreasing $\bar{M}_{n}$ of the polystyrene blocks. This can be interpreted as that too short polystyrene blocks cannot form domains efficiently, as demonstrated by the well known SBS block copolymers. ${ }^{6}$ 
Table V. Effects of $\bar{M}_{n}$ of the PSt block on mechanical properties of the block copolymer ${ }^{a}$

\begin{tabular}{|c|c|c|c|}
\hline \multirow{2}{*}{$\begin{array}{c}\bar{M}_{n} \times 10^{-4} \\
\text { of PSt } \\
\text { block }\end{array}$} & Tensile strength & Elongation & Permanent \\
\hline & $\mathrm{MPa}$ & $\%$ & $\%$ \\
\hline 1.65 & 13.6 & 426 & 10 \\
\hline 1.14 & 13.1 & 402 & 10 \\
\hline 0.86 & 11.9 & 417 & 12 \\
\hline 0.57 & 8.8 & 450 & 17 \\
\hline
\end{tabular}

a PSt:PPO $=3: 7$.

Table VI. Effects of the block copolymer ${ }^{\mathrm{a}}$ on the mechanical properties of the blend ${ }^{b}$

\begin{tabular}{|c|c|c|c|c|}
\hline $\begin{array}{c}\text { Block } \\
\text { copolymer/ } \\
\text { Blend }\end{array}$ & $\begin{array}{l}\text { Tensile } \\
\text { strength }\end{array}$ & Elongation & $\begin{array}{l}\text { Permanent } \\
\text { set }\end{array}$ & Shore \\
\hline$\%$ & $\mathrm{MPa}$ & $\%$ & $\%$ & \\
\hline 0 & 4.7 & 363 & 19 & 66 \\
\hline 1 & 10.0 & 717 & 11 & - \\
\hline 2 & 11.5 & 721 & 6 & 46 \\
\hline 3 & 9.9 & 732 & 12 & - \\
\hline 4 & 9.2 & 751 & 12 & 44 \\
\hline 6 & 8.4 & 878 & 15 & 44 \\
\hline 8 & 7.1 & 788 & 19 & 43 \\
\hline 10 & 7.1 & 797 & 22 & 41 \\
\hline
\end{tabular}

a Composition of the block copolymer, PSt : $\mathrm{PPO}=3: 7$ (weight ratio).

b Composition of the blend, PSt : ECHR $=3: 7$ (weight ratio).

When epichlorohydrin rubber was blended with polystyrene alone, the tensile strength was rather low and the permanent set somewhat large. However, if $1-4 \%$ of the above mentioned multiblock copolymer of styrene and propylene oxide was added to the blend, the mechanical properties were improved quite a lot, as shown in Table VI. It indicates that the multiblock copolymer can act as a compatibilizer and only a small amount of it is needed. If the block copolymer was used more than $4 \%$ of the blend, the tensile strength decreased
Table VII. Glass transition temperature of polystyrene (PSt), epichlorohydrin rubber (ECHR), and their blends

\begin{tabular}{lcc}
\hline Samples & $T_{\mathrm{g} 1}$ & $T_{\mathrm{g} 2}$ \\
\hline PSt & - & 114 \\
ECHR & -15 & - \\
Blend of PSt $:$ ECHR $=3: 7$ & -5 & 109 \\
$\begin{array}{l}\text { Blend of PSt }: \text { ECHR }=3: 7 \text { and } \\
2 \% \text { copolymer }\end{array}$ & -1 & 85 \\
\hline
\end{tabular}

and permanent set increased with further increasing amount of compatibilizer. Dynamic mechanical analysis shows that $T_{\mathrm{g}}$, $s$ of the blend are $-5^{\circ} \mathrm{C}$ and $109^{\circ} \mathrm{C}$, while those of the blend with addition of $2 \%$ block copolymer are $-1{ }^{\circ} \mathrm{C}$ and $85^{\circ} \mathrm{C}$ (Table VII). The inward shift of $T_{\mathrm{g}}$ 's as compared to those of individual homopolymers denotes that the block copolymer enhances the compatibility of epichlorohydrin rubber and polystyrene. It can be explained by the similar structure between PPO block of the block copolymer and the epichlorohydrin rubber. However, the less shift of $T_{\mathrm{g} 1}$ is probably due to some difference between the structure of epichlorohydrin rubber and PPO blocks and also a larger difference between their molecular weight.

\section{REFERENCES}

1. D. H. Richards and M. Szwarc, Trans. Faraday Soc., 55, 1644 (1959).

2. A. V. Tobolsky and A. Reinbaum, J. Appl. Polym. Sci., 8, 307 (1964).

3. H. Kawamura, K. Takemoto, and M. Imoto, Kobunshi Kagaku, 26, 148 (1969).

4. G. H. Hsiue, Proc. Natl. Sci. Counc., Repub. China, Part A, 5, 60 (1981); Chem. Abstr., 97, 24959y (1982).

5. X. Chen and H. Q. Xie, Chinese J. Appl. Chem., 4(2), 22 (1987).

6. M. Morton, "Encyclopedia of Polym. Sci. Technol, Vol. 15, H. Mark and N. G. Gaylord, Ed., Interscience Publishers, New York, N. Y., 1971, p 508. 